\section{Liste der Preisträger des 93. Deutschen Röntgenkongresses}

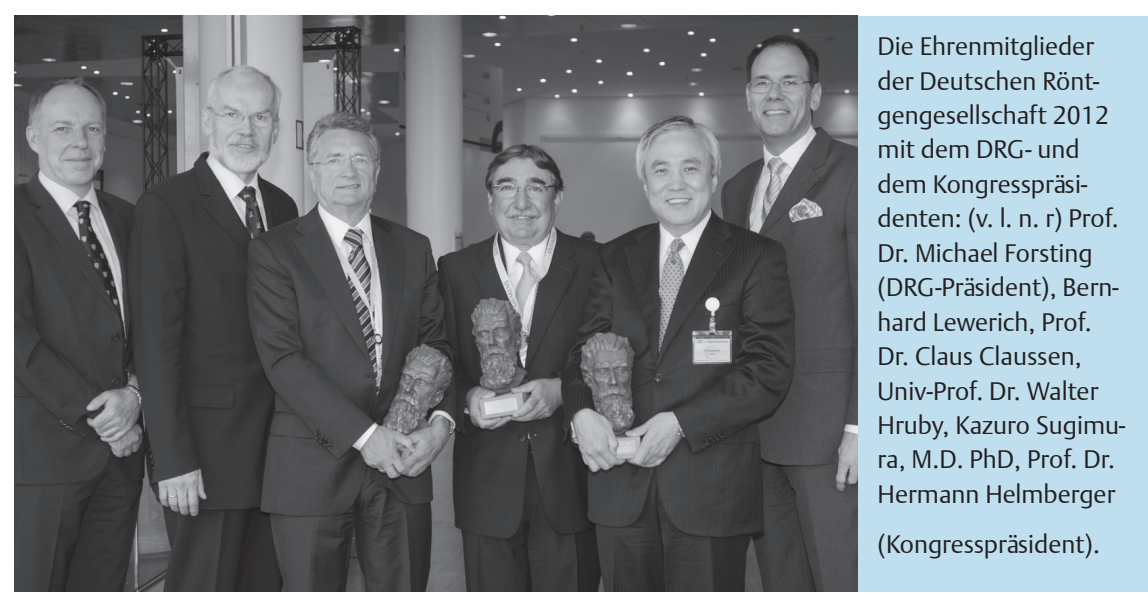

\section{Wilhelm-Conrad-Röntgen-Preis $\checkmark$ \\ > PD Dr. med. Thomas W. Schlosser (Darmstadt) \\ > Prof. Dr. med. Hans-Joachim Mentzel (Jena)} (Essen)

\section{Wilhelm-Conrad-Röntgen-Ring $\nabla$ \\ - PD Dr. med. Marc Dewey (Berlin)}

\section{Alfred-Breit-Preis \\ $\nabla$ \\ > Prof. Dr. med. Rolf W. Günther (Aachen)}

\section{Albers-Schönberg-Medaille $\nabla$ \\ > PD Dr. med. Peter Landwehr (Hannover)}

\section{Walter-Friedrich-Preis \\ $\nabla$ \\ > PD Dr. med. Ulrike Attenberger (Mannheim)}

\section{Werner-Porstmann-Preis $\nabla$ \\ > Dr. med. Philipp Wiggermann (Regensburg)}

\section{Innovationspreis der Wachsmannstiftung} $\nabla$

> Prof. Dr. med. Martin Mack (München)

- Prof. Dr. med. Michael Uder (Erlangen)
- Dr. med. Florian Mayer (Münster)

- PD Dr. med. Rolf Janka (Erlangen)

\section{Promotionspreis \\ $\nabla$}

- Dr. -Ing. Andreas Fieselmann

(Erlangen)

- Dr. med. Fabian Rengier (Heidelberg)

D Dr. med. Jens Theyson (Essen)

\section{Young Investigator Award}

$\nabla$

- Mario Zeller (Würzburg)

- Dr. med. Katja Hueper (Hannover)

\section{Posterausstellung}

$\nabla$

Summa cum laude

- Matthias Gawlitza, Leipzig

> Caroline Jung, Hamburg

> Hansjörg Rempp, Tübingen

Magna cum laude

- Christoph Rehnitz, Heidelberg

- Carola Heneweer, Kiel

- Jost Kloth, Heidelberg

- Christian Siedentopf, Innsbruck

- Jürgen Weidemann, Hannover

(Erlangen)

- Prof. Dr. med. Claus-Peter Heußel (Heidelberg)

- Prof. Dr. med. Michael Knauth

(Göttingen)

- Brigitte Wendt (Westerstede)

$\checkmark$ Prof. Dr. med. Peter Huppert

Cum laude

- Isabel Kaiser, Leipzig

- Wolfgang Freund, Ulm

- Nikita Garnov, Leipzig

- Nicole Marques, Bonn

\section{Röntgenquiz}

$\nabla$

- 1. Preis: Dr. Robert Ritzel, Hamburg

2. Preis: Dr. Gudrun Manshausen, Bornheim

3. Preis: Dr. Wolfgang Gelmetti, Unna

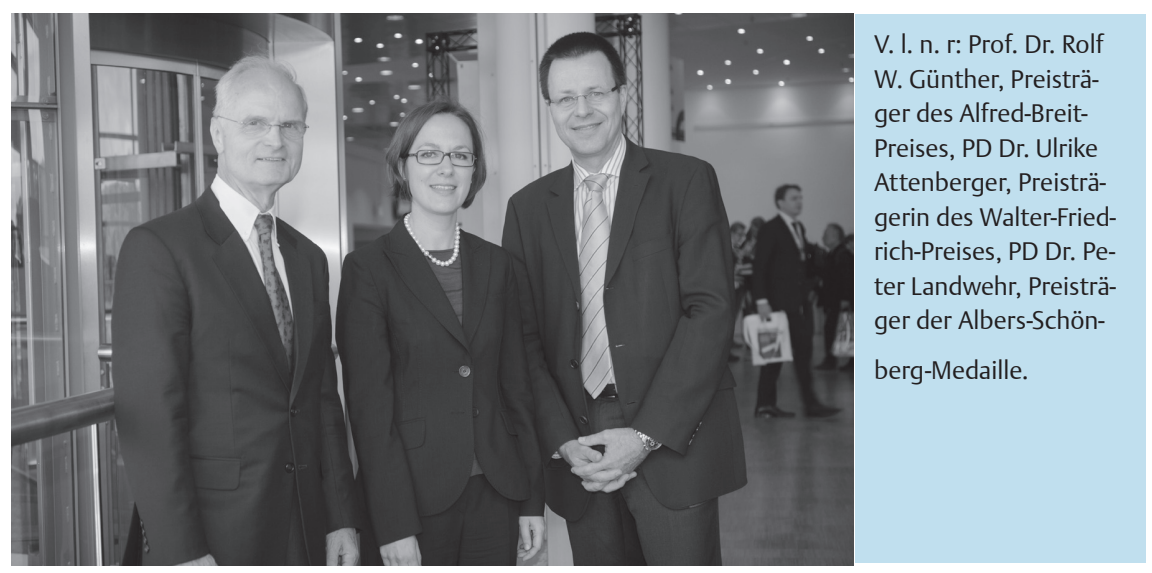

